\title{
nordon
}

\section{The Nordic Region}

- leading the way in green growth

Outcomes of the Nordic prime ministers' green growth initiative 2011-2015

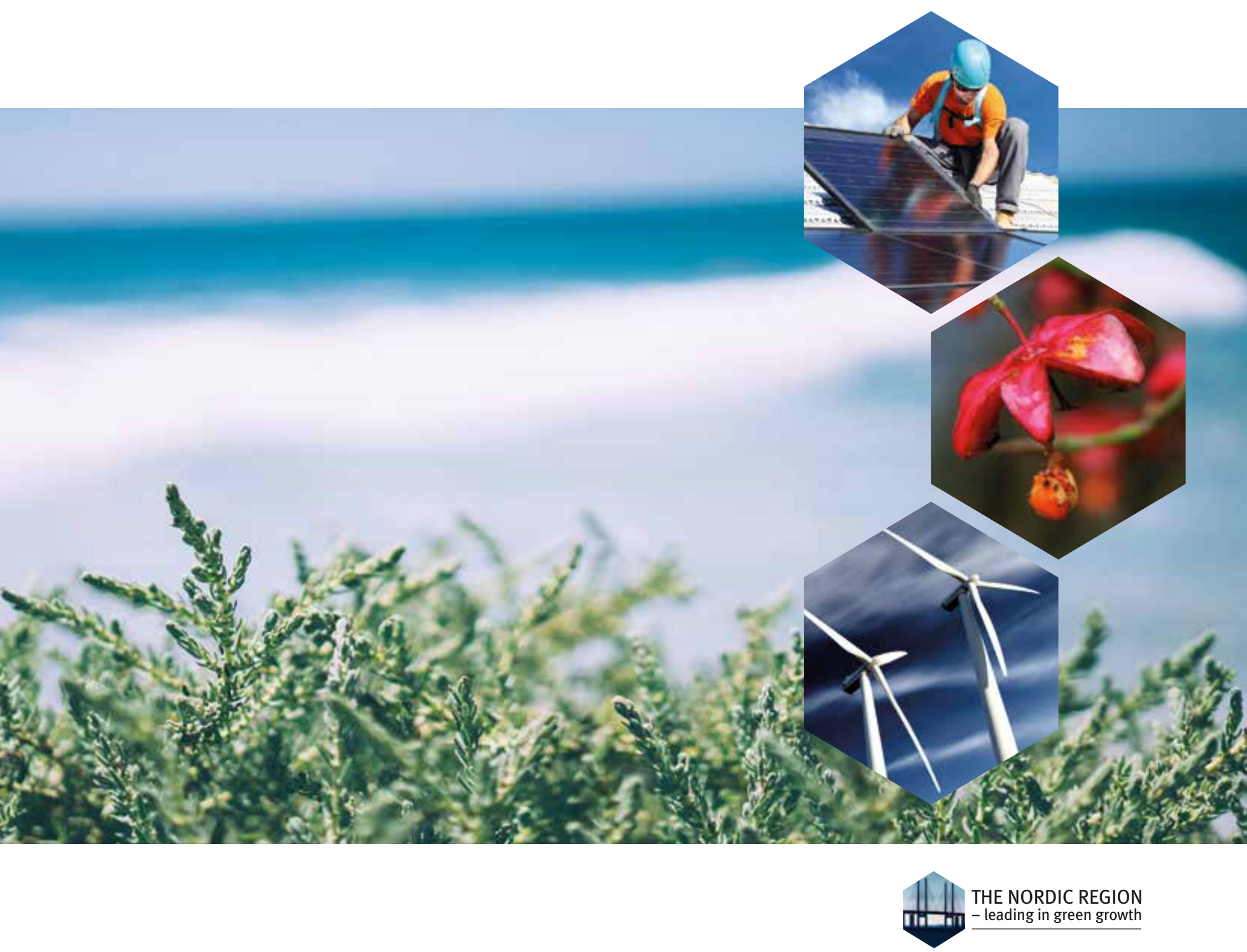


The Nordic Region - leading the way in Green Growth

Outcomes of the Nordic prime ministers' green growth initiative 2011-2015

ISBN 978-92-893-4716-7 (PRINT)

ISBN 978-92-893-4717-4 (PDF)

http://dx.doi.org/10.6027/ANP2016-774

ANP 2016:774

(c) Nordic Council of Ministers, 2016

Layout: Gitte Wejnold

Photos: Norden.org, NordForsk: Joakim Lund, Unsplash.com

Font: Meta LF

Paper: Munken Polar

Copies: 500

Print: Rosendahls-Schultz Grafisk

www.norden.org/nordpub

\section{Nordic co-operation}

Nordic co-operation is one of the world's most extensive forms of regional collaboration, involving Denmark, Finland, Iceland, Norway, Sweden, and the Faroe Islands, Greenland, and Åland.

Nordic co-operation has firm traditions in politics, the economy, and culture. It plays an important role in European and international collaboration, and aims at creating a strong Nordic community in a strong Europe.

Nordic co-operation seeks to safeguard Nordic and regional interests and principles in the global community. Common Nordic values help the region to solidify its position as one of the world's most innovative and competitive.

\author{
Nordic Council of Ministers \\ Ved Stranden 18 \\ DK-1061 Copenhagen K \\ Telefon (+45) 33960200
}

www.norden.org 


\section{The Nordic Region - leading the way in green growth}

Outcomes of the Nordic prime ministers' green growth initiative 2011-2015 


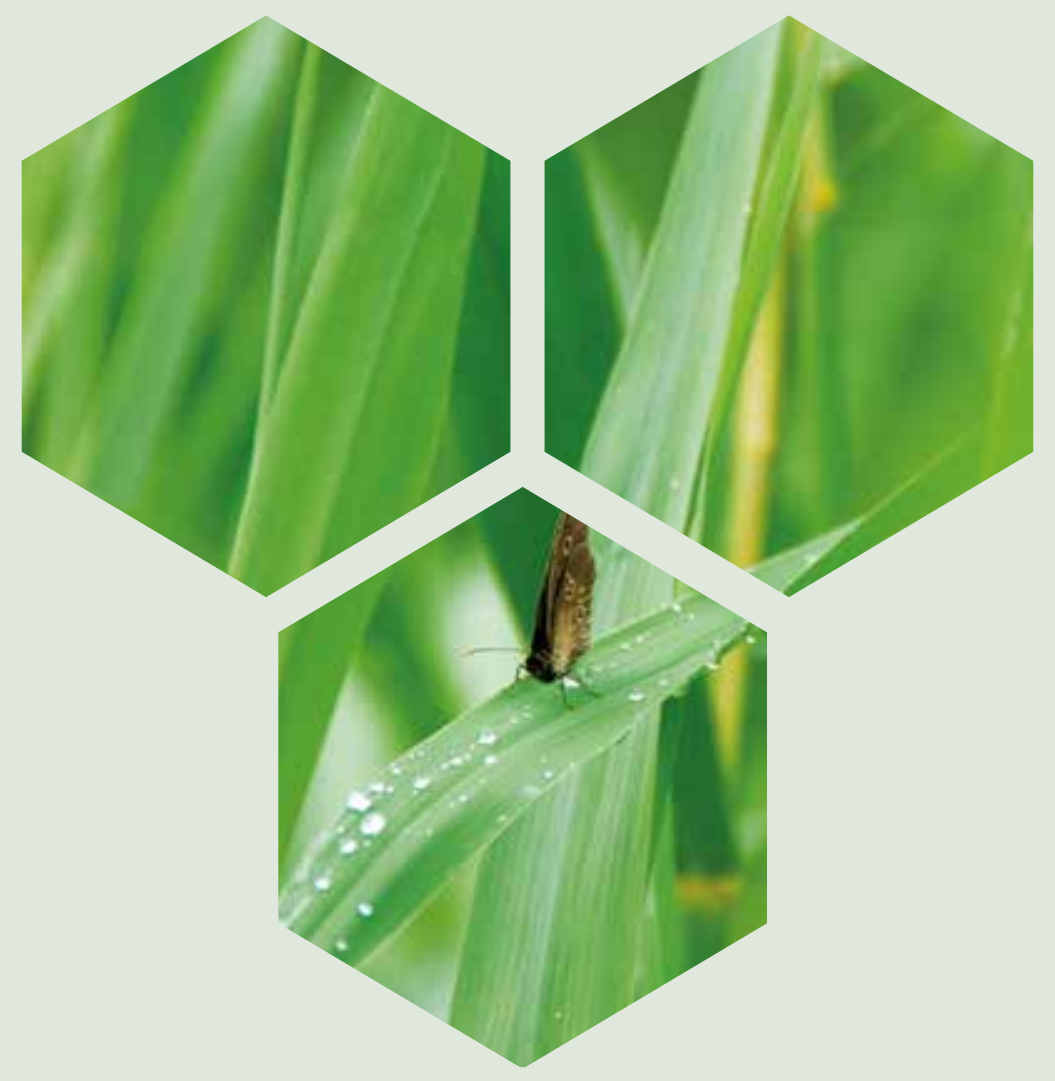




\section{Contents}

$7 \quad$ Introduction

$8 \quad$ Nordic test centres for green solutions - great potential within the fields of bioeconomy and biorefineries

10 Education and research that promote green growth:

a. Children and young people

b. Universities and higher education

c. Adult education

d. Research and innovation

17 Increased flexibility for consumers in the Nordic electricity market

18 Green technical norms and standards

a. The Nordic Region sets the standards for sustainable building

b. Nordsyn-market surveillance of ecodesign and energy labelling in the Nordic Region

21 Green procurement in the public sector

22 Development of technology and methods for processing waste

a. Reducing food waste

b. Resource-efficient recycling of textile and plastic waste

26 Integration of environment and climate issues in development aid: supporting sustainable fossil fuel subsidy reform

$27 \quad$ Funding of green investments and businesses

For more information on the projects, please visit www.norden.org/greengrowth 


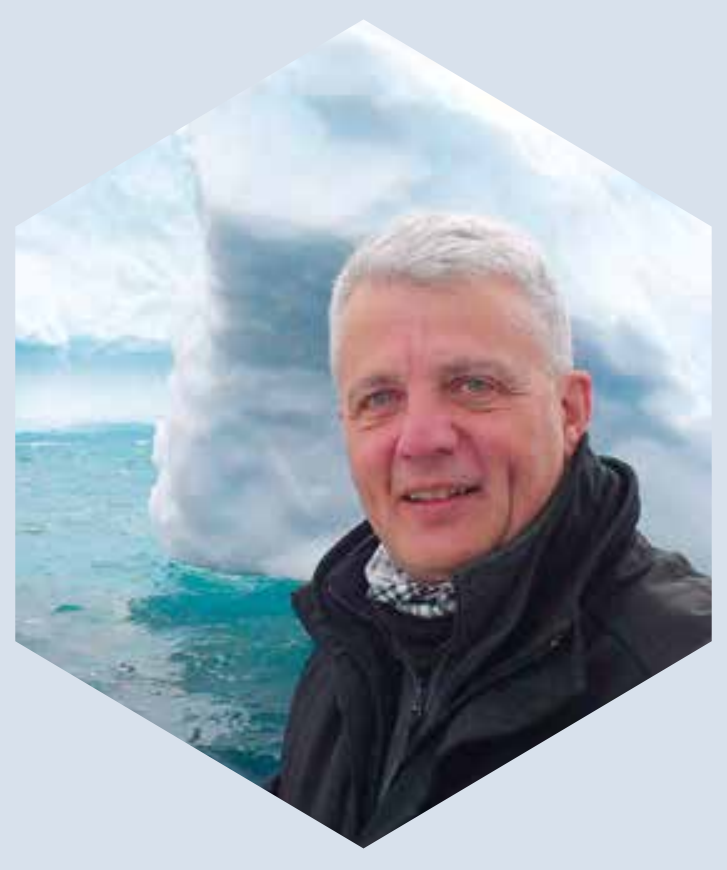


Green Growth has been a priority programme of the Nordic Council of Ministers since it was launched by the Nordic prime ministers in November 2011 as "The Nordic Region - leading in green growth".

The prime ministers' vision for the programme was to identify areas in which the Nordic countries could build on existing positions of strength, improve co-ordination between the countries, and lead the way in relation to developments in the European Union. As Secretary General of the Nordic Council of Ministers, it gives me great pleasure to report that the Nordic Region has made great advances in all these areas over the last five years.

The various initiatives under the green growth initiative span a variety of areas: education and research, the electricity market, the construction sector, ecodesign and energy efficiency, collaboration on green public procurement, waste management, bioeconomy and green test centres, development aid, and green investments. All these initiatives seek to contribute to tackling the world's major environmental and climate challenges, as well as to help the Nordic countries improve their market positions in selected areas.

The Nordic Council of Ministers granted a total of DKK 66 million to the eight focus areas in the period 2012-2015. Most initiatives were completed by the end of 2015 , but some continue into 2016 and beyond. Although the long-term outcomes will not be felt until later, we are already noticing that there is interest in the outcomes of the projects already completed.
The Green Growth programme has built a solid base from which the Nordic Council of Ministers can continue its work on innovative green solutions, and I am convinced that the programme has helped us to strengthen Nordic skills, improve co-ordination between the Nordic countries, and provide the Nordic Region with an international profile as a region where green growth, innovation, and sustainable development are a reality - not just a vision for the future.

\section{Dagfinn Høybråten}

Secretary General

Nordic Council of Ministers 


\section{Nordic test centres for green solutions - great potential within the fields of bioeconomy and biorefineries}

This project has resulted in new policy recommendations for the establishment of a Nordic collaboration on biorefineries. These recommendations emphasise the ability of the bioeconomy to help develop rural districts and coastal areas and to generate growth in small and medium-sized companies. This is expected to result in continued collaboration bioeconomics in a Nordic context. In addition, a Nordic Bioeconomy Panel was set up in 2016 to stimulate this co-operation.

Work on the test centres began in 2012 with the report Mapping of Green Energy Test Centres which identified 45 existing test and demonstration facilities in the Nordic Region. The report showed that there is potential for greater Nordic collaboration in the field of energy testing and pointed out potential benefits in sharing the high investment and operating costs.

The next step was to take a closer look into Nordic collaboration on biorefineries, in order to optimise the utilisation of biological resources that are currently either underused or not used at all. More than $50 \%$ of all resources in the primary sector currently go to waste so the potential for optimisation is enormous.

The first results of the biorefinery project are very promising and the report Development of the Nordic Bioeconomy from 2015 identified huge potential for further cooperation on the bioeconomy in the Nordic Region.

Specifically, the results show that the Nordic Region is ahead of the game when it comes to moving beyond bioenergy into the area of upscaling and upgrading resources within the food and feed industry. Existing technologies make it possible for the entire value chain of products - from health, through food and food ingredients, chemicals and functional materials, to energy and soil improvement - to be upgraded to use organic resources, and to be expanded upon.

The Nordic countries complement each other within the field of bioeconomy. Stronger Nordic cooperation could not only draw on the advantages of shared resources, but could also help attract external funding and promote Nordic expertise within the EU. The green growth project on test centres has demonstrated the potential for the Nordic Region to further cement its position. 

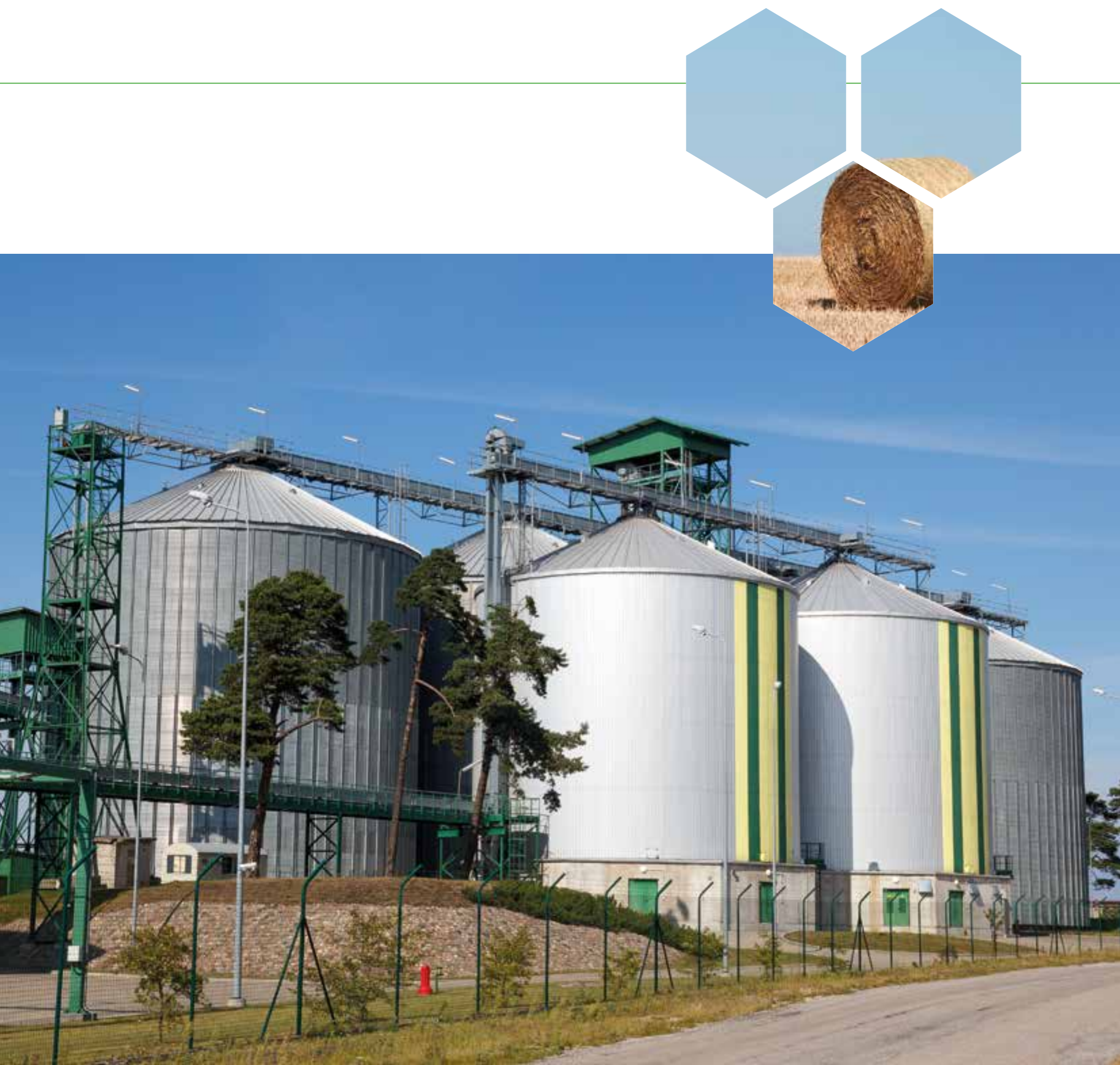


\section{Education and research that promote green growth}

Seven green growth projects have been set up in the area of education and research. The projects span the entire education spectrum, from children and young people to adults, and from students to researchers. The common objective is to strengthen sustainable development and green growth by disseminating knowledge and know-how.

\section{EDUCATION FOR CHILDREN AND YOUNG PEOPLE}

\section{The Great Nordic Climate Challenge}

The Great Nordic Climate Challenge was launched in 2014 and is a competition for pupils between the ages of 12 and 16 in the Nordic Region. The "challenge" focuses on making a difference for the environment and combines teaching materials, themes, and competitions on energy, climate, and the environment.

The aim of this project is to provide Nordic teaching materials that promote collaboration between pupils across the region, and that make pupils more aware of their responsibility and what they can do to help resolve climate and environmental challenges.
The content is fully integrated in the Norden i Skolen (the Nordic Region in the School www.nordeniskolen.org) learning portal, which is managed by the Federation of the Norden Associations. This platform has more than 17,000 registered users and reaches over 80,000 pupils in the Nordic Region.

The theme for the Climate Challenge 2015 was food waste, sustainable purchasing habits, and methods for waste processing, inspired by the Nordic prime ministers' green growth projects on these topics. More than 180 school classes took park and over 400 teachers throughout the Nordic Region were involved.

In 2016 the teaching materials will be launched in Greenlandic, Faroese, and Sami to make the concept more accessible to children and young people in the Arctic region. The project will continue into 2017.

\section{Biophilia}

The Biophilia educational programme explores the interplay between science, creativity, technology, and music, with the aim of supporting the learning and innovative abilities of children and young people through interdisciplinary and creative learning methods.

Nordic researchers, scientists, artists, and teachers have developed teaching ideas for the project in collaboration with the Icelandic artist Björk, who initiated the project based on her Biophilia album. The teaching materials are available at www.biophiliaeducational.org. 

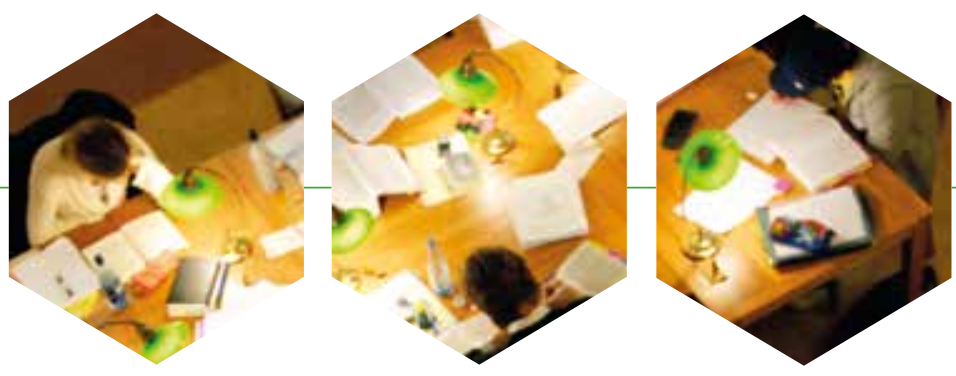

\section{HIGHER EDUCATION}

\section{Nordic Master's Degree in Green Growth}

The Nordic Master's Degree in Green Growth is a two-year master's programme that brings together the sharpest minds on sustainable development in the Nordic Region.

The 120-ECTS master's programme will be set as a collaboration between at least three universities in the Nordic countries, including the Faroe Islands, Greenland, and Åland. The language of instruction is English in order to attract Nordic, European, and international students.

The Nordic Master's degree programme was introduced in September 2015, and the consortium behind it was put together in October. Students will be admitted to the programme in 2016 and 2017.

\section{Green Campus Network: implementation of Rio+20}

This project has involved a major survey of how sustainable development measures are implemented in Nordic universities and higher education institutions.

The aim has been to increase collaboration between institutions and to engage decision-makers in implementing the Rio+20 sustainability goals relating to the operation of educational institutions in general, as well as to the specific educational programmes they offer.

The results were presented in 2015 in a report that provides an overview of the level of sustainability in Nordic educational institutions and describes the steering mechanisms, drivers, and barriers that influence the implementation. In addition, 152 academics participated in a Sustainability Literacy Test as part of the global Higher
Education Sustainability Initiative, which indicated a high level of sustainability across the board in all the Nordic countries.

\section{Nordic Entrepreneurship Islands}

Globalisation and demographic changes create challenges for islands and remote rural areas. One example is the fact that young people with high career aspirations, especially young women, leave their island communities due to the lack of opportunities.

Nordic Entrepreneurship Islands was a one-year pilot project exploring and mapping the development of entrepreneurial education on eight selected Nordic islands. The project studied the mechanisms and strategies that help young people to obtain the entrepreneurial skills required to start new businesses, such as contacting investors and business networks. 
The following islands/areas have been involved in the project: Bornholm in Denmark, Andøya in Norway, Gotland in Sweden, Pargas in Finland, Iceland, Greenland, the Faroe Islands, and Åland. The results of the project will be presented at a conference in November 2016.

Read more at norden.org/nei

\section{ADULT EDUCATION}

\section{Knowledge for sustainable development}

Nordic adult education organisations have launched a pilot educational programme in sustainable development. Its objective is to "train trainers" in teaching sustainability issues and to explore how a greener awareness can be promoted locally and globally.

Sustainable development requires more conscious actions and clear pathways towards making sustainable choices. This project has sought to develop a Nordic concept for teachers and volunteers in civil society networks to promote this way of thinking.

Nineteen students from across the Nordic Region took part in the first round of the project, with a further 20 being enrolled in the 2016 course. The projects are linked to issues relevant to the local environment that the participants represent, the goal being the creation of a strong network across the region that promotes awareness of green issues and is based on a common Nordic education in sustainable development.

The methods and educational ideas of the pilot programme have so far been presented at seven international conferences and seminars and in several publications.
The project was evaluated in 2015 and, based on the positive results of the pilot programme, the Nordic network for Adult Learning will document and develop a manual for the methods used so that it can be offered as a permanent educational programme for adult education providers in the Nordic Region.

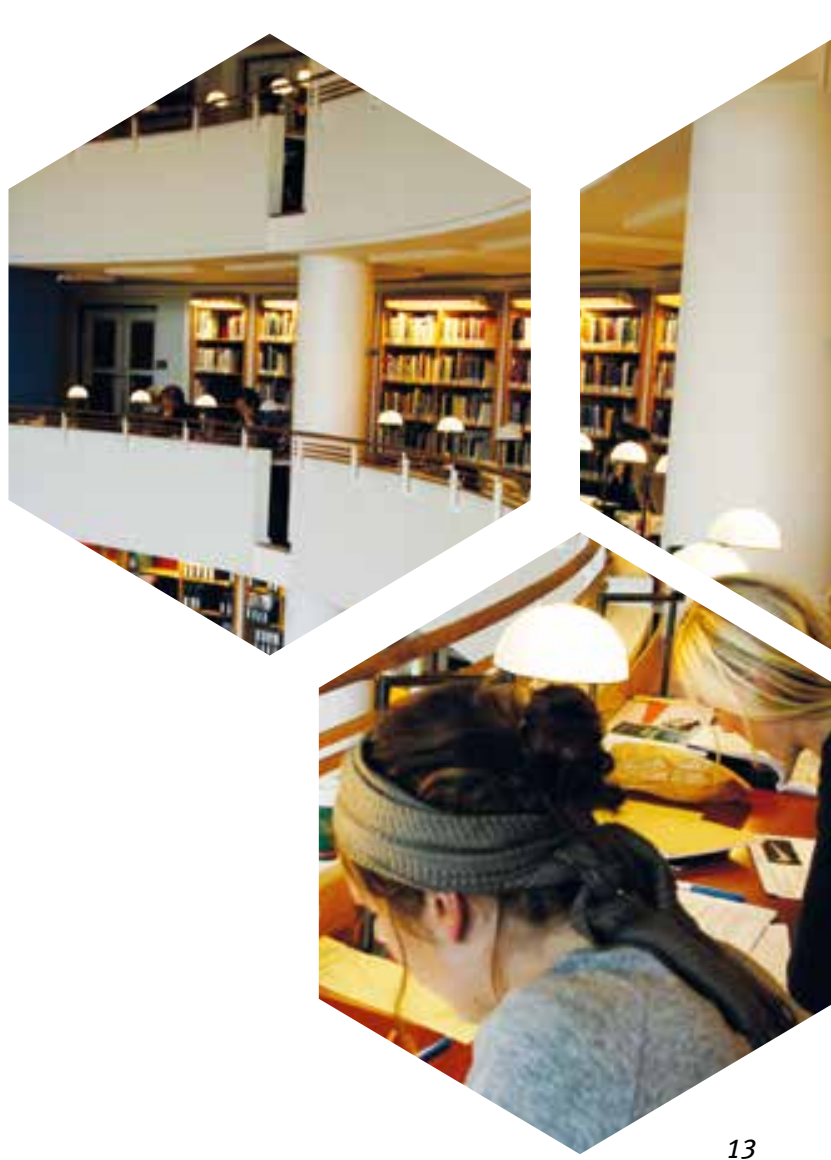




\section{RESEARCH AND INNOVATION}

\section{Green Growth - Understanding Societal Challenges}

The largest single initiative under the education and research element of the green growth initiative is a joint Nordic research and innovation project which seeks to better understand and develop the green transition in the Nordic Region and worldwide. The project in part follows up on the results from The Nordic top-level research initiative which produced new solutions in the areas of climate, energy, and the environment.

The Nordic countries are committed to achieving ambitious climate goals by 2050 , with a view to developing energy-efficient and lowcarbon societies. Achieving these goals requires an extensive green transition in every aspect of Nordic society.

The five Nordic countries are now joining forces to develop a major interdisciplinary research and innovation programme focusing on green growth: The Green Growth Research and Innovation Programme.

The new programme is a joint venture of the main funders of research and innovation in the Nordic countries, as well as of three institutions under the Nordic Council of Ministers, namely NordForsk, Nordic Innovation, and Nordic Energy
Research. The overall budget is just under EUR 9 million.

The programme will bring leading Nordic researchers in the fields of climate, environment, and energy together with the business community and innovation environments, as well as stakeholders in industry, policymaking, and civil society.

The aim is to develop and share new knowledge, methodologies, and technologies in the area of green growth, and to stimulate innovative solutions that can accelerate the transition towards sustainable Nordic societies. A key aim is to identify the social conditions associated with green growth and the implications this knowledge has for policy.
The programme focuses on areas of research and innovation related to green growth where the Nordic countries have common interests and can contribute exceptional solutions internationally. Synergies will be generated with other relevant initiatives in the Nordic Region and internationally, such as the Nordic research programme Responsible Development of the Arctic: Opportunities and Challenges - Pathways to Action, the Nordic Bioeconomy Programme, and The Top-level Research Initiative. The programme will promote broad use of the results in education, research, business, and administration.

A call for proposals opened in spring 2016 and projects are expected to start in 2017. 


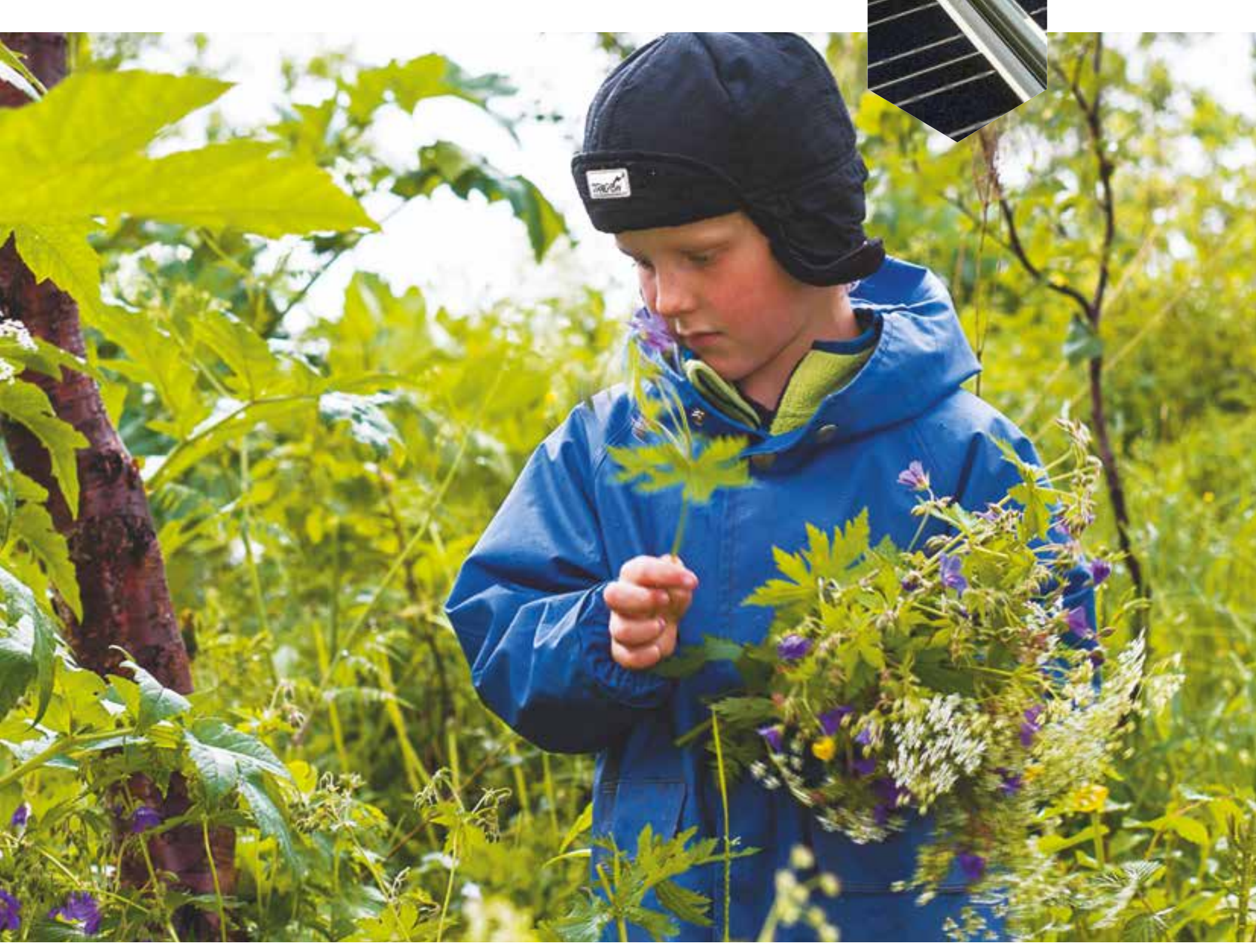




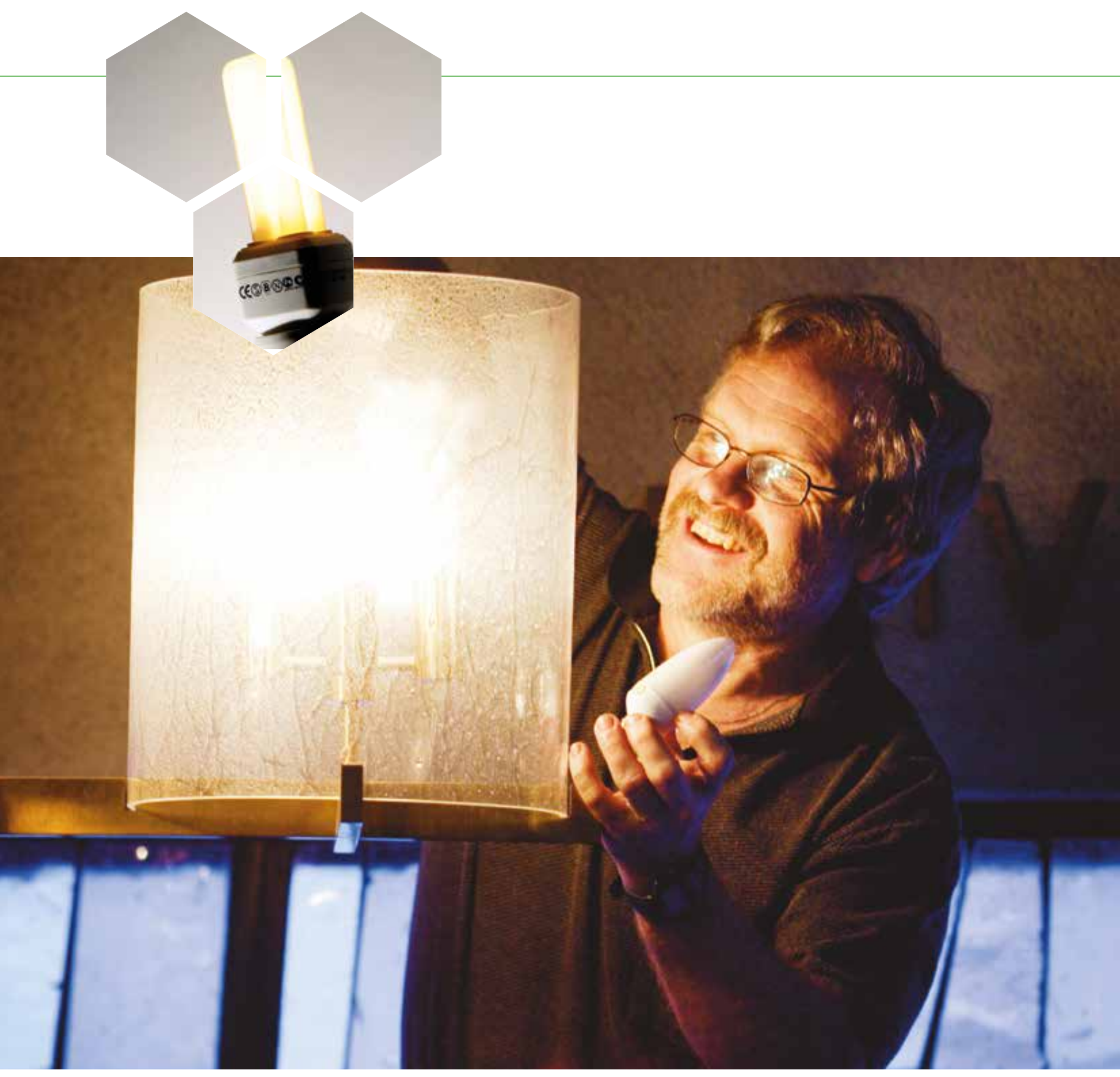




\section{Increased flexibility for consumers on the Nordic electricity market}

The common Nordic electricity market is the most integrated macro-regional energy market in the world. One of the projects under the Nordic prime ministers' green growth initiative set out to explore whether a Nordic strategy is needed to increase consumer flexibility on the demand side. The conclusion was that a common strategy is not needed, but that there is great potential for increased co-operation in the Nordic electricity market.

The project "Demand response in the Nordic electricity market - input into a strategy on demand flexibility" was designed to evaluate the potential for a common Nordic strategy in order to enhance consumer flexibility within the Nordic electricity market.

Although the need for consumer flexibility varies among the Nordic countries as well as within each country, in general, future actions taken at a national level regarding the electricity market should enhance flexibility. The aim should be increased flexibility in terms of consumption, production, and storage, as well as transmission.

However, based on the outcome of the project mentioned above, it has been decided that a common strategy for the Nordic electricity market to enhance consumer flexibility is not needed.

It was concluded that: "No specific measures to promote demand flexibility should be implemented without a better understanding of how the value of demand flexibility will develop in view of the likely changes in the Nordic power system."

Although a common strategy to enhance consumer flexibility in the Nordic electricity market is not needed, and despite the fact that the efficiency of the Nordic power market is generally high, further improvements can be made.
This could be to secure a better consumer demand response to market signals - e.g. through standardised data formats to facilitate an automated response to price signals - or to improve the ability of electricity grid tariffs to reflect the underlying grid costs to create more transparency in the market.

The Nordic electricity regulators are responsible for following up on this project. 


\section{Green technical norms and standards}

Three main projects have been started within this focus area. The projects focus on building standards, ecolabelling for building renovations, and market surveillance of ecodesign and energy labelling.

\section{The Nordic Region sets the standards for sustainable building}

The goal of this project was to promote a common Nordic market for sustainable building, as well as to have an influence on European standardisation in selected areas. By facilitating a joint project between the Nordic standardisation bodies, the programme has shown that it is possible to develop joint Nordic standards and to influence European standardisation. Approaching the EU authorities as a regional group has proven to be a major advantage.

Relevant authorities and representatives from the building industry in the Nordic countries initially identified three key areas for the Nordic Region and it was decided to draft a Nordic input into standards pertaining to: sustainable renovation of existing buildings, indoor climate and voluntary classification standards, and future EU regulations on product and building declarations.

The Nordic standardisation bodies subsequently drafted a Nordic input for submission to the CEN, the European standardisation body, thus laying the foundations for a clear Nordic stamp on future regulation within these areas. At the same time, joint standardisation is seen as a means to remove trade barriers among the Nordic countries themselves.

Along with the activities of the CEN, a dialogue with relevant directorates within the European Commission has been initiated to promote Nordic standards in relation to European legislation in the areas touched upon in the project.

The process will continue in relevant working groups in the CEN throughout 2016, and there will be ongoing dialogue with the Commission on regulatory aspects.

\section{Ecolabelling for buildings} In addition to the project titled "Leading European regulation - the Nordic Region sets the standards", a complementary project titled "The Swan ecolabel for building renovations" is underway.

The project focuses on developing criteria for the Swan ecolabel for building renovations. The goal is to have the draft criteria published for public review in 2016 and 


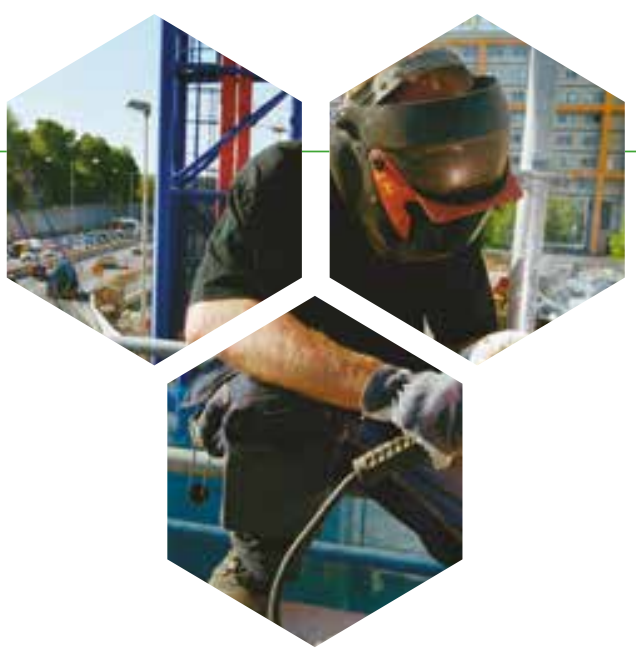

adopted by the Nordic Ecolabelling Board by spring 2017. The Swan ecolabel is for use by private and public contractors who carry out sustainable renovation.

\section{Nordsyn - market surveillance of ecodesign and energy labelling in the Nordic Region}

The Nordsyn project has shown that energy loss amounting to EUR 28 million has been prevented at a market surveillance cost of EUR 2.1 million in the Nordic countries - i.e. a thirteen-fold return on investment. The project shows clearly that market surveillance is cost-efficient, especially when countries cooperate.

The aim of Nordsyn has been to improve Nordic market surveillance of ecodesign and energy-labelling regulations linked with the EU Ecodesign Directive. The primary target groups are Nordic market surveillance authorities (MSAs) and corresponding European MSAs, as well as producers of energy-related products.

Thanks to Nordsyn, Nordic MSAs now regularly share their own test results along with feedback and answers from the European Commission. They also discuss relevant questions and plans on an ongoing basis.

\section{Nordsyn has provided a platform} to develop Nordic co-operation on a day-to-day basis, produce information materials, and undertake requested studies together, which has strengthened the position of the Nordic countries in EU negotiations.
Nordsyn has received funding from the Nordic Council of Ministers for 2016-2017, which allows the project to continue with a focus on strategic Nordic products, information to producers, and challenges for market surveillance.

Three main reports have been published based on the Nordsyn projects, along with a series of guidelines and other information materials for producers and regulators:

- Nordsyn: Market surveillance effects and costs

- $\quad$ Strategic Nordic Products: Heat pumps

- $\quad$ Survey of SMEs on ecodesign and energy labelling

All the publications are available at www.norden.org/nordsyn 


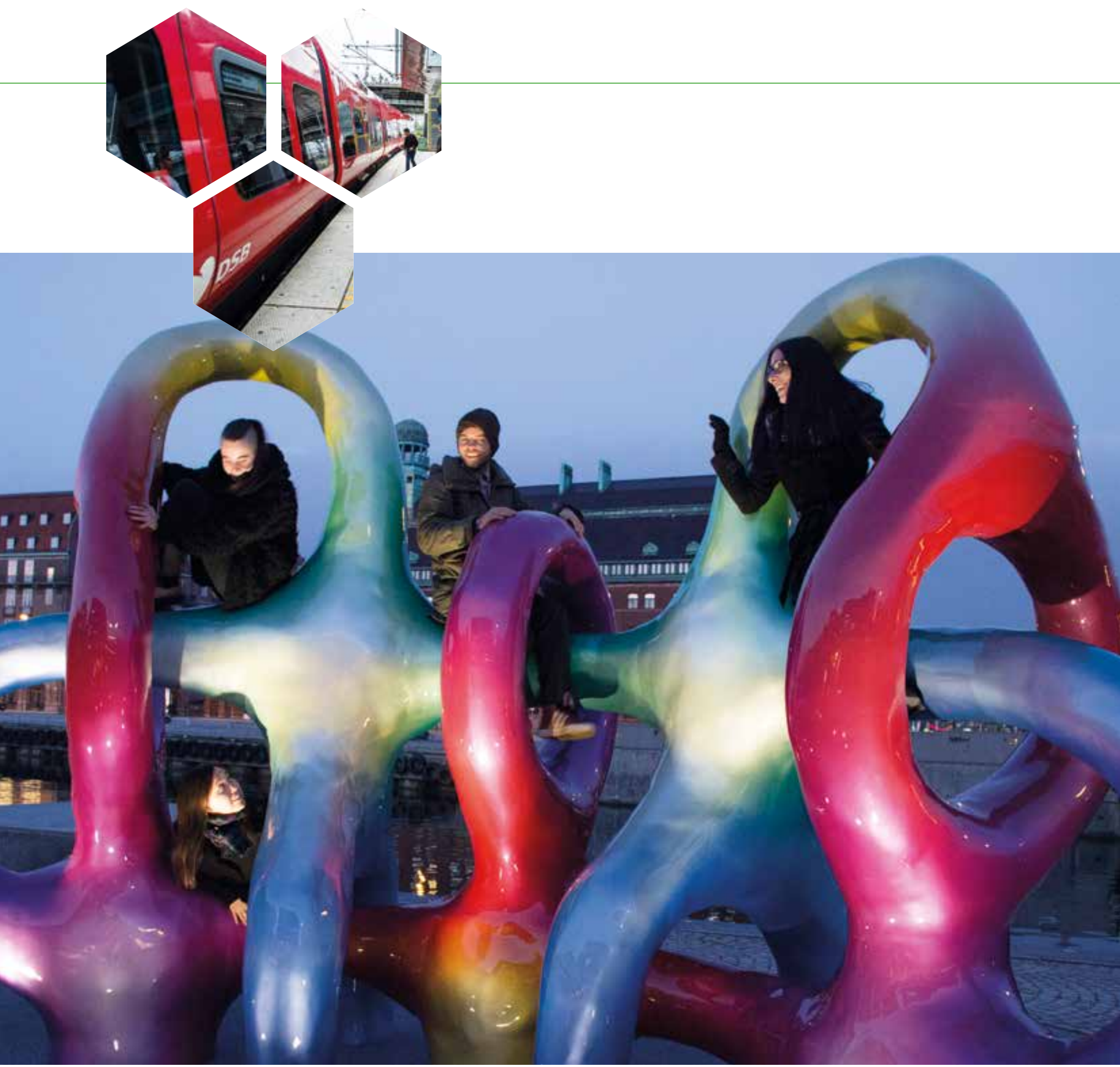




\section{Green procurement in the public sector}

The main objective of this project will be to strengthen green growth in the Nordic countries by way of a common approach to green public procurement, in terms of policy development as well as on a more practical level. The project focuses on areas with a competitive advantage for Nordic stakeholders and will strengthen Nordic co-operation on public procurement of clean technology and other eco-innovative solutions.

A common approach is needed at the practical level if public procurement is to be an effective tool in achieving green growth. The creation of a critical mass of frontrunner public procurement entities regarding common needs and ways of conducting procurement sends a strong signal to the market. This in turn enables Nordic companies to develop the capacities needed to be able to address the needs of public procurers.

The primary objective of the project is to increase green growth through far-reaching and well-informed public procurement practices in the Nordic metropolitan areas.

This is achieved by establishing a capacity-building network and peer-to-peer collaboration between the metropolitan areas in the Nordic countries. This network will conduct workshops based on best practice on themes such as transport, and joint market dialogue for common needs.

In addition, the legal framework on public procurement represents an important aspect of procurement practices. Five national workshops examining the potential for integrating ecolabels and environmental management systems in public procurement were conducted in spring 2016 based on the new EU Procurement Directives. Each national seminar will be used as a basis for a Nordic guide on how to implement the directive. A common approach to interpreting EU legislation will benefit suppliers of green solutions across the Nordic markets. 


\title{
Development of technology and methods for processing waste
}

\begin{abstract}
A number of projects have been launched as part of the prime ministers' green growth initiative that deal with the circular economy. They look at ways of improving the processing of plastic and textile waste and of reducing food waste in the Nordic Region. The projects have mapped current shortcomings, proposed models for future solutions, and formulated policy recommendations for Nordic collaboration. The results are expected to make a significant contribution to Nordic co-operation in the coming years and have attracted considerable international interest.
\end{abstract}

\section{Reducing food waste}

Three projects have been initiated on food waste as part of the prime ministers' green growth initiative. The objectives of the three projects have been firstly to develop knowledge about food waste in primary production, secondly to help producers to date-label food in a way that minimises food waste, and thirdly to promote the safe and effective distribution of surplus food to people in need.

The primary production project has resulted in the formulation of a definition for food waste and production losses in primary production. Various data collection methods have been tested for selected products in line with this definition, and an estimate of the total losses in primary production in the Nordic countries has been made. The results from the project can be used to help identify measures to reduce losses in primary production.

Results from the date-label project show that the interpretation of datelabelling legislation differs among Nordic countries. A correlation between shelf life and food waste was observed, which highlights the need for the food industry and retailers to implement measures to extend shelf life. Proposals for harmonisation measures will be disseminated as a result of the project, as will information to help people better understand the difference between "best before" and "use by", as well as consumption times once food packaging has been opened.

The project on food redistribution involved food banks, NGOs, businesses, and authorities. The resulting key recommendations are aimed at redistribution stakeholders, donors, and authorities that are likely to help increase food redistribution while ensuring a high level of food safety. Recommendations include increased collaboration among all relevant stakeholders, the developing the ability of national and regional food banks to act as systems operators for the redistribution system, and the development of sustainable funding schemes that will allow 

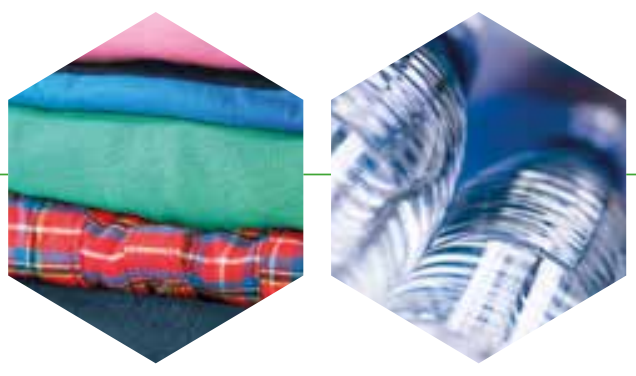

redistribution to fulfil its potential as a tool for food waste reduction, enhanced social security, and sustainable business models.

By continuing the Nordic collaboration on food waste, it is expected that the region will play a leading role and present a strong common vision in the EU. The results of the projects are already part of the European collaboration, and the project group has presented Nordic experiences, models, and tools to avoid food waste to the EU.

\section{Resource-efficient recycling of plastic and textile waste}

This project focused on developing joint methods and techniques for achieving more resource-efficient recycling of waste. The focus was on plastic and textiles, with the aim of generating benefits for both the environment and the economy. The results show that there is huge potential for improving resource efficiency, reducing emissions of greenhouse gases, and generating new jobs in the region.
Three textile projects and three plastic projects have been conducted, and the experts involved in them have produced a range of reports and guidelines for consumers, producers, and the various participants in the Nordic reuse and recycling industry, as well as recommendations for Nordic policymakers.

The plastic waste recycling projects have focused on plastic packaging from household waste, plastic waste at recycling centres, plastic from electronic waste, plastic markets, and hazardous substances in plastic recycling. In the area of textiles the projects have sought to increase the collection, sorting, reuse, and recycling of textiles in the region as well as to study the impact of textiles exported from the Nordic Region.

The results show that there is the potential to increase the collection and recycling of plastic and textile waste in the Nordic Region considerably. For example, the countries can potentially collect and

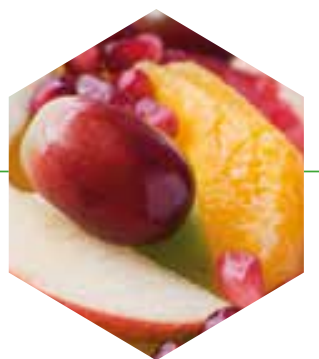

recycle a further 700,000 tonnes of plastic from municipal waste streams alone. Similarly, a considerable quantity of plastic delivered to recycling centres and plastic from electronic waste could be used much more than is currently the case.

The projects pertaining to plastics have proposed specific strategies and tools to show how private and public players in the plastic value chain can help to increase their collection and recycling of plastic. Two of the projects have also developed policy recommendations for Nordic decision-makers, aimed at increasing material recycling of plastic waste.

The results from the projects on textiles show that the increased collection, sorting, reuse, and recycling of textiles can reduce the environmental impact of textile use in the Nordic Region, boost the competitiveness of the region, and generate green jobs. Annual consumption of new textiles in the Nordic countries is 350,000 tonnes, 
but only 120,000 tonnes of used textiles are collected each year.

A new Nordic commitment to textile reuse and recycling is currently being launched and has already attracted considerable interest from companies, municipalities, and others interested in participating in a joint Nordic effort to reduce textile waste.

Nordic decision-makers have been presented with clear objectives and expert recommendations for the Nordic Region to take the lead in increasing the recycling and reuse of plastics and textiles, with clear proposals for how to continue these efforts.
Work on an extended producer responsibility (EPR) system and innovative new business models can, if applied, lead to textiles having a longer usable life and potentially create green jobs both in the Nordic Region and internationally. With regard to plastics, ongoing efforts relating to hazardous substances and markets can be used as part of efforts relating to the circular economy package presented by the European Commission, as well as in policy development in the Nordic Region on the road towards achieving a circular economy.

In the area of textiles, three studies have been published that show the potential for a doubling of the amount of textiles collected, reused, and recycled in the Nordic Region. The objective is that textiles will be reused as often as possible during the course of their functional lifetime, and then be recycled. This type of restructuring could potentially lead to over 4,000 new jobs in the region.

The results from the plastic and textile projects have been presented in European and international forums, with the aim of inspiring more environmentally sound consumption, production, and processing of plastic and textiles.

All publications are available at www.norden.org/waste 


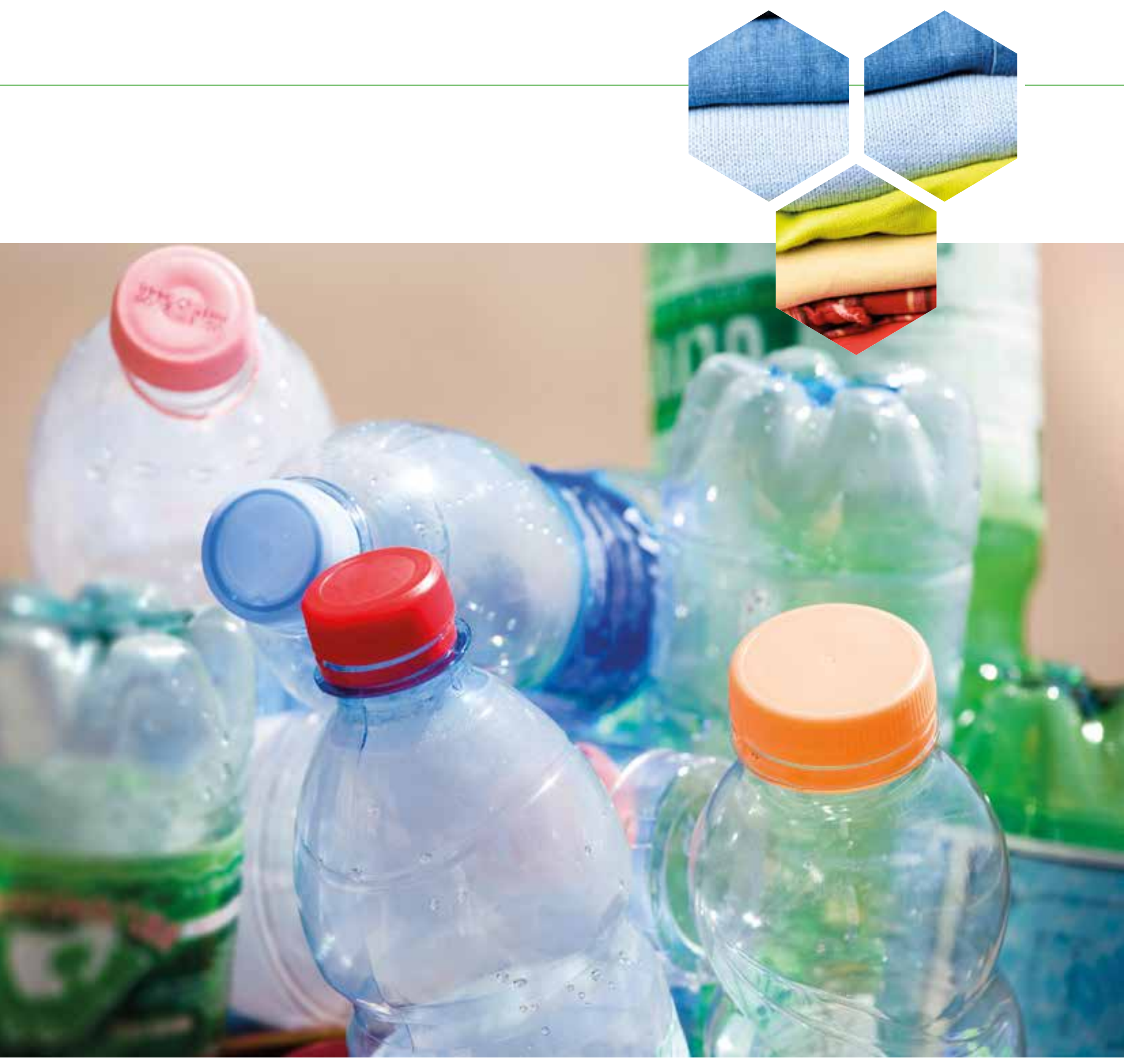




\section{Integration of the environment and climate in development aid: supporting sustainable fossil fuel subsidy reform}

The project focused on fossil fuel subsidies and showed how emerging and developing countries can phase out such ineffective and environmentally harmful public subsidies. Research results indicate that a reform of these subsidies (totalling around USD 550 billion in 2014) could reduce global CO2 emissions considerably, by six to thirteen per cent by 2050. The project worked with and across 20 emerging and developing countries in the lead-up to the Paris negotiations, and a joint Nordic follow-up is now under consideration.

The project on fossil fuel subsidy reform enabled the development of an economic model that calculates the national emissions reductions from phasing-out state support for fossil fuels.

Across the 20 countries the research found average reductions following reform of $11 \%$, or a total of 2.8 gigatonnes of $\mathrm{CO} 2$ across 20 countries by 2020 . By comparison, global emissions are around 355 gigatonnes. The financial savings to governments average USD 93 per tonne of $\mathrm{CO} 2$ abated, so while reducing emissions usually costs money, this model outlines potential savings.

The research also presents scenarios for how the savings from reform could be invested into social safety nets, better energy efficiency, and renewable energy, thereby improving emissions reductions to around $18 \%$. In this way, the Nordic initiative is supporting the transition to a green economy in developing countries by demonstrating ways of financing new initiatives.

Throughout 2015 the research was fed into successful international processes and shared directly with the climate negotiators of the 20 countries in the study. Countryspecific webinars (Indonesia) and side events in Geneva (27 countries), Bonn (35 countries), and Paris gave weight to the issue. An invitationonly roundtable and subsequent press conference for the launch of the full report in Bonn secured coverage in the press and social media (e.g. Bloomberg and $\mathrm{CNN}$ ).
The research (which has been downloaded 4,000 times to date) complemented Nordic efforts as part of the Friends of Fossil Fuel Subsidy Reform international communiqué and received backing from 40 countries and the Nordic prime ministers at COP21. Thirteen countries included the issue within their national climate contributions, including Morocco - with which the project worked closely - in line with its ambitious plans for the expansion of renewable energy, efficiency, and availability.

Having laid many of the foundations on this issue throughout 2015 , it is hoped that momentum can be consolidated through implementation efforts at COP22 and in general, as well as with Morocco and the other partner countries involved in the research. 


\section{Funding of green investments and businesses}

Three reports have been produced in connection with the project on green investments. One conclusion is that the use of government-sponsored marketbased economic policy instruments on a large scale is the best way to support green investments. Additionally, the overall results show that there is further potential for green investments, especially in resource-intensive sectors such as energy, transport, and material and waste management.

Other conclusions include findings such as that the institutions in which the Nordic countries have a significant ownership (i.e. the Nordic Investment Bank (NIB) and the Nordic Environment Finance Corporation (NEFCO)) are already deeply involved in funding green investments and environmental initiatives.

However, the analysis also shows that their modest market share limits their influence in relation to total investment need. Consequently, these greater Nordic efforts in financial institutions as a whole are marginal compared with general economic policy instruments, which can influence the entire economy.
In 2013, the Nordic Council of Ministers decided to broaden the analysis, working with the environmental sector to include the use of market-based instruments that can promote green investments in the Nordic countries.

The analysis compared the countries' ideas on how they can better correct market failures by applying economic policy instruments, such as by compensating for low prices on $\mathrm{CO} 2$ emissions.

The overall results show that there is further potential for green investments in the Nordic Region, in particular investments in resource-intensive sectors such as energy, transport, and material and waste management. The report also encourages the countries to closely monitor whether their economic policy priorities generate an appropriate incentive for green investments.

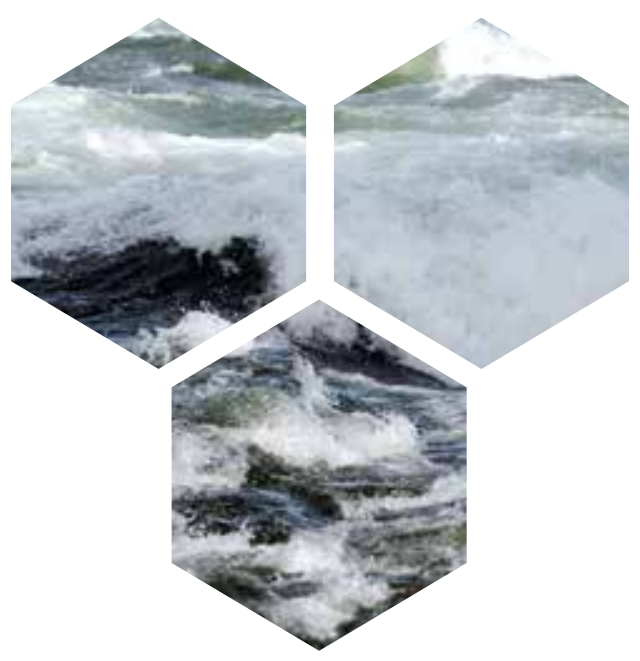




\section{norden}

Nordic Council of Ministers

\section{Ved Stranden 18}

DK-1061 København K

www.norden.org

"The Nordic Region - leading in green growth" was the Nordic prime ministers' joint green growth initiative from 2011 to 2016 under the auspices of the Nordic Council of Ministers.

The aim was to create joint Nordic solutions to shared problems in selected areas:

1. Developing Nordic test centres for green solutions

2. Working together on education, training, and research for green growth

3. Promoting the flexible consumption of electricity

4. Working together on green technology norms and standards

5. Working together on green procurement in the public sector

6. Developing techniques and methods for waste treatment

7. Promoting the integration of environmental and climate considerations into development aid

8. Co-ordinating and improving funding for green investment and companies. Nordic partnerships in these areas make sense for a number of reasons and will provide advantages that are currently only partially utilised.

Nordic partnerships create a larger market, they allow the Nordic Region to lead the way politically in the EU/EEA, they improve joint infrastructures, and they provide a critical mass for future developments.

This folder presents the main results from the prime ministers' green growth initiative.

More information is available at norden.org/greengrowth 